\title{
How To Setup a Continuous Experimental Teaching System: Case Study On The Tourism Management Program
}

\author{
Jun $\mathrm{Hu}^{1,2}, \mathrm{Mu}$ Zhang ${ }^{2} \&$ Xiang Huang ${ }^{2}$ \\ ${ }^{1}$ Management School, Jinan University, Guangzhou 510632, Guangdong, China \\ ${ }^{2}$ Shenzhen Tourism College of Jinan University, Shenzhen 518053, Guangdong, China \\ Correspondence: Xiang Huang, Shenzhen Tourism College of Jinan University, Shenzhen 518053, Guangdong, \\ China. E-mail: huangxiang@sz.jnu.edu.cn
}

\author{
Received: January 25, 2014 Accepted: March 13, 2014 Online Published: March 28, 2014 \\ doi: $10.5539 /$ hes.v4n2p70 \\ URL: http://dx.doi.org/10.5539/hes.v4n2p70
}

\begin{abstract}
Chinese higher tourism education witnesses 32-year continuous innovation and exploration since the reform and opening policies. And it has gained many successful experiences in the aspects of talents cultivation mentality, nurture target, subject construction, curriculum arrangement and training module. However, it suffers the shortage of tourism professionals in tourism management. Disjunction between college education and market demand is one of the important reasons. Many-year teaching reform proves that tourism experimental teaching centre is able to encourage students' innovative idea and practice ability to realize seamless connection of talent cultivation and market demand. What's more, experimental teaching system can not only offer basic education for undergraduates, it also designs connectional experimental teaching system based on collaborative education between undergraduate and graduate education. It possesses basic dimension, professional dimension, comprehensive dimension, innovative dimension and dynamic dimension with the feature of basic recognition experiment, professional ability cultivation, disciplinary application innovation and industrial application development. Hence it is expected to train practical and innovative talents of different level for tourism industry and offer example and reference for graduate's innovative education in major of tourism management.
\end{abstract}

Keywords: continuous experimental teaching system, tourism management program, undergraduate and graduate education, collaborative development

\section{Introduction}

21 st century is regarded as the times of fast development in knowledge economy, information technology and economy globalization. Knowledge, innovation, capacity have become the important elements of survival and development of a country, a region, an industry, an enterprise even a person in this competitive era. So the education of 21st century will attach importance on cultivation of compound quality, innovation awareness and ability. Besides the requirement of the times, market demand with industry characteristics is another influential factor for university talents training. With the development for more than 30 years, Chinese tourism confronts with great challenge and opportunity in the wave of global economy. Therefore, it is an urgent problem to train excellent professional tourism talents with the quality of application, comprehension, and innovation.

Recent years, Shenzhen tourism college of Jinan university summarized an important solution after 14 years' exploration and innovation. That is, it combines theory with practice, knowledge with skill, talents training with market demand with breaking the limitation among curriculum, specialty and students to form ability-training-oriented experimental teaching system according to disciplinary development. Hence, this paper takes tourism experimental teaching centre as the example to discuss how to establish and improve connected interdisciplinary and multi-level experimental teaching system. It possesses the purpose of achieving this system's cohesion between two levels of undergraduate and graduate to promote collaborative growth of undergraduate and graduate education in major of tourism management. What's more, it is expected to offer some exploration and demonstration on training of multi-level compound and innovative talents of tourism management in Chinese university.

\section{Profile of Foreign and Chinese Experimental Teaching}

Now the reform on teaching and research mechanism focused on experimental teaching centre to develop 
teaching and scientific research simultaneously (Zhang, Zhao, \& Luo, 2009). All the facts prove that experimental teaching in other countries has accumulated abundant experience in teaching method, content and management mechanism etc. which will benefit Chinese higher education especially graduate education.

In the "Education Revival plan in 2003-2007" from education ministry approved by the state council, and in the second meeting on higher education hold by education ministry, there clearly proposed to set up experimental centre in the college to meet the needs of improvement of school running level and education quality. Recent years, many Chinese universities have attach more importance on the establishment of experimental centre. In the process, they discussed the necessity, importance, organizational structure, resource outfit, management mechanism, operation model and openness degree to eventually reach the open experimental teaching agreement of "with the target of training applicable, innovative and compound talents". For instance, Yang (2003) studied various existing open experimental teaching models and their connotations in Chinese universities, and pointed out to realize the sharing of equipment by opening the lab; Yi (2005) emphasized the significance of lab for talent education in university; Xie et al. (2005) suggestd the construction idea and operation model on separating theoretical and experimental course with making new experimental teaching system, having open management on lab and increasing open experiment; D. Wang (2010) researched on integrated teaching mode and progressive teaching level adopted by communication lab in training applied and innovative talents which had gained distinct experimental teaching outcome; Starting from solving the problem of lab centre development, $\mathrm{Wu}(2010)$ concluded to improve hardware and software of experimental teaching centre in the aspects of management standardization, course optimization, teacher promotion and management opening; J.-W. Wang (2010) analyzed six experimental modules adopted by engineering training centre in comprehensive university, that is, the type of big engineering, complete openness, multi-disciplinary integration, practiced innovation, project research and combination among production, learning and research; Liu and Zhang (2010) thought lab construction should carry out the measurement of scientific planning, reinforcement of quality project, execution of project management in lab construction and scientific lab management. What's more, innovation credits were recommended to arrange teacher-guided scientific research training, work on project lab openness, adding scientific competition in daily teaching; Li (2005), Gu (2006), Chen (2010) and $\mathrm{Hu}$ (2010) studied on professional experimental teaching, and made proposal according to its constraint elements on construction and developmen; $\mathrm{Li}$ and Jiang (2006) found that restaurant management experiment set in major of tourism management which emphasizes practice ability has grown to be a new teaching reform module. In conclusion, experimental teaching centre is playing more and more important role in talent training of tourism management.

The above analysis proves that Chinese and foreign scholars hold the same idea that experimental teaching centers were able to enhance students' innovation idea and creative ability. So far, Chinese research mainly learns from the modules in advanced countries. However, there are few outcomes in the aspects of specific discipline, arrangement and cohesion of graduate and undergraduate teaching target. So this paper chooses the practice of Shenzhen tourism college of Jinan university as the example to discuss the establishment of collaborative experimental teaching system to effectively connect graduate and undergraduate in the major of tourism management.

\section{Design and Application of Connectional Experimental Teaching System}

\subsection{The Profile of Tourism Experimental Teaching Centre of Jinan University}

Since Jinan University established tourism experimental teaching centre in Shenzhen tourism college in 2005, it has persisted in experimental teaching idea of three languages (English, computer and Chinese) three terms, three abilities (learning ability, practice ability and innovation ability). And it has designed relevant experimental teaching curriculum according to the characteristics of three majors (Business English, E-commerce and tourism management) and 7 specialty directions to form hierarchical experimental teaching system from basic experiment to comprehensive experiment to design experiment to innovation experiment and visualized experimental teaching system with campus cultural activity and scientific innovation activity and scientific research activity and open experimental project. What's more, it has built internship experimental teaching base in and out of college to improve students' ability in tourism scenic spot, hotel, travel agency, golf, landscape design and planning and MICE etc to reach the goal of "cultivating excellent professional tourism talents with practice and innovation ability to meet satisfaction of industry."

After 5 years' construction, tourism experimental teaching centre has built an advanced, efficient and open lab management mechanism and operation mechanism and excellent staff with reasonable structure and rich experience in theoretical and practice teaching. It has also set up favorable experimental teaching environment with advanced equipments and abundant network sharing resource to play supportive role in internship 
experimental teaching in the major of tourism management, e-commerce and business English to train groups of qualified talents for all trades in the society.

\subsection{Multi-Dimensional Analysis on the Design of Connectional Experimental Teaching System}

The major of tourism management is a practice and applicable subject which requires close connection of tourism practice to achieve win-win outcome in discipline development and talent training. Zhang Liming has pointed out that modern tourism management talent should possess T-structure knowledge. That is, in width, there is solid knowledge and broad horizon; in depth, it should specialize in tourism industry; in ability, it needs three-dimensional structure of professional operation skill, knowledge renewal and innovation management ability and comprehensive collaborative ability. In psychology, it encourages high social responsibility, aggressiveness and scientific exploitive spirit (Zhang, 1999). Therefore, higher education in tourism management should attach more importance on students' comprehensive training in the aspects of "compound quality, knowledge structure, practice ability" to guarantee its seamless connection with society

Hence, considering about applicable characteristics of tourism management major, the authors try to establish and improve experimental teaching basic system to achieve cross and integration of five dimensions.

\subsubsection{Basic Dimension}

As for freshmen who changed their exam-oriented education to college quality education, professional guidance seems to be full of significance. So the purpose of establishing experimental teaching basic dimension is to develop and complete students' cognitive structure which mainly refers to guide them to form correct learning habit and attitude, possess basic professional conception and professional ability. However, students in different level usually have different experimental demands, so unification of basic knowledge helps them gap the difference quickly. What's more, making full use of lab condition encourages students know and experience experimental scientific questions as many as possible to strengthen their professional quality to build solid foundation for further study.

\subsubsection{Professional Dimension}

When students are sophomores, they start the stage of specialty positioning. With solid foundation in previous stage, they are able to spot interests in specialty. Then it is quite necessary to have specialty classification. There involves many specialties in tourism experimental centre in Shenzhen tourism college which includes major of tourism management (directions of tourism management, scenic spot planning and landscape design, golf and leisure management, hospitality and event management), E-commerce and business English etc. Learning and research objects range from single to complex, plane to tridimensional, display to planning which indicates complicated discipline background of tourism. Therefore, it is necessary for students finding out their own interests after unified learning. The specialty's division is very clear, and classification outstands their specialty characteristics which also urge students be adapted to the applicable field in the specialty with comprehensive knowledge.

\subsubsection{Comprehensive Dimension}

Tourism experimental teaching centre designed series of experimental course for tourism management major to synthetically use the knowledge such as society, economy, history, ecology, environment, architecture, art, technology and materials to strengthen the relationship among teaching content, form and organization in order to smooth cohesion and transformation among various courses to improve students' integrated ability. Therefore, under different professional settings of tourism management, electronic commerce and business English, compound quality should be emphasized to students, various experimental elements needs students' perception in learning. At the same time, all new technological means and ideas should be synthetically adopted in experimental teaching, what's more, compound network materials should be fully use to carry out experimental courses. It supplies new form for textbook compiling, arrangement of teaching content, teaching method and interaction between teachers and students. This new experimental teaching form of "Network University" and global classroom greatly improves the efficiency of compound knowledge teaching. Because it can spread knowledge and communicate research outcome in larger space even in virtual space so as to realize the democratic dream of "everybody has the right to receive education".

\subsubsection{Innovative Dimension}

Students in major of tourism enjoy their compound inter-disciplinary background to enable them better rational thinking ability than regular tourism students in art discipline. They think it is unified for rational and emotional thinking; practice-oriented experiment steps are usually presented by concrete and logical forms. Hence, tourism experimental teaching centre makes series of general courses which are popular quality education form of 
university all over the world. University in Hong Kong and Taiwan pay much attention to it. As we all know, experimental teaching enable tourism management major more innovation spirit. Idea with cultural connotation can not live without acquisition of compound knowledge and training of synthetically ability. When designing collaborative experimental teaching system between graduate and undergraduate, idea generalization helps teacher and student create more ideas to bring reform in design thoughts and form to achieve mutual improvement of teaching and learning.

\subsubsection{Dynamic Dimension}

Tourism possesses obvious application characteristics, and its development needs support and participation from society and industry, the concern towards present and future, mastering its essence and feature dynamically. Therefore, tourism experimental teaching centre focuses on above elements. On one hand, in terms of curriculum arrangement, it makes changeable experimental teaching curriculum. What's more, it will connect with vertical and transversal project in college and university to equip students with effectively integrate theory by practice. On the other hand, in the planning of innovation internship, it will adopt internship teaching of "mixing practice with learning". In spring and summer vocation and other holidays, students will be arranged in relevant tourism enterprise, golf court, IT enterprise, logistics companies to have career-oriented internship which will help students experience enterprise's operation mode and development of the industry. All these will build solid professional foundation for students working for the society.

\subsection{Collaborative Connectional Experimental Teaching System for Graduates and Undergraduates}

Modern tourism discipline has transformed from single to cross, from internal to divergent. And its traditional tourism service mode is apt to have synthetically development of technology, service and application. Therefore, considering about characteristics of modern tourism discipline, tourism experimental teaching centre forms ability-training-centered experimental teaching idea. In order to break single system of traditional teaching mode to set up student-oriented teaching mentality, it is necessary to strengthen connection of graduates' experimental course when meeting satisfaction of undergraduates' course. So the authors designed combination of stage with interaction experimental teaching system fitting for tourism management to present experimental teaching demand in different levels, and figure 1 shows it.

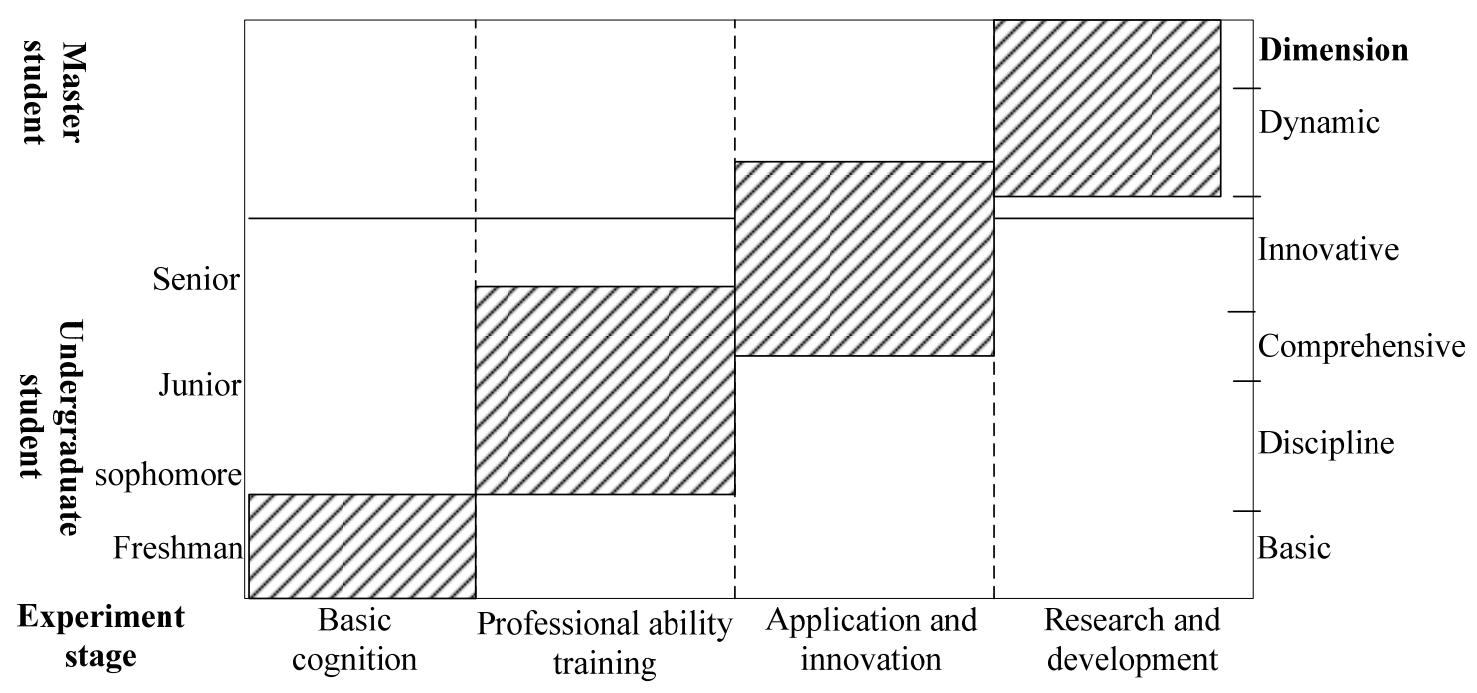

Figure 1. Continuous experimental teaching system

For stage, experimental teaching system orienting graduate and undergraduate collaboration can be divided into four stages: Basic cognition experiment stage, professional ability training ability, disciplinary application innovation stage, industry application research stage. The corporation and interaction of these four stages achieves interaction and collaboration of graduate and undergraduate education in experimental teaching target. This experimental teaching system makes specialty teaching more interactive, systematic and scientific.

\subsubsection{Basic Cognition Experiment Stage}

Teaching lab at this stage will arrange experimental teaching course according to foundation dimension to get 
through the hinder and obstacle of specialty based on students' character in different levels. Selective choice and unified teaching can effectively improve the efficiency and multi-functional role in experimental teaching. And it mainly focuses on freshmen on comprehensive experimental teaching.

There includes three levels at this stage: The first is cognitive or demonstrative experiment. It trains students overall perception on specialty knowledge in form of in-class lecture. What's more, demonstration function of multimedia can be emphasized to offer a lot of resource and case studies for students to make experiment teaching more active and accessible. The second level is verification and simulation experiment. Experiment can be used to prove important conclusion in theoretical teaching. Experimental teaching environment is adopted to recur and observe operative process of management. This level is students-centered and teacher-guided. For example, "Tourism management information system" helps student comprehensively know about the whole process of information transformation of tourism enterprise. The third level is application and production experiment. According to the requirement of theoretical requirement, students are asked to handle with experiment operation, design and production by their practice. For example, establishment and maintenance of a website helps students know about the whole procedure of a commercial website.

\subsubsection{The Stage of Professional Ability Training}

Experimental lab will arrange experimental teaching courses mainly according to specialty dimension and synthetical dimension. It will not only take different characteristics of all disciplines into account, it will also pay attention to comprehensive training on ability which mainly refer to the synthetical experimental teaching for sophomores and juniors.

Experimental course at stage includes four aspects: firstly, professional simulated experiment. Establishment of relevant experimental course in various specialties is able to cultivate and foster students' specialty interests to help them select the topic for further research. It mainly adopts the means of in-class teaching and operation in lab. For example, there designs certain course of certain discipline: network information and security for E-commerce, tourism management information system for business English, there are other courses shared by relevant discipline, simulation of electronic airlines for major of tourism management and E-commerce, databank design for all the disciplines.

Secondly, it will next to the empirical experimental project. Experimental internship base in college can train students' practice ability with the main approach of skill practice. For instance, students in major of hospitality and event management are arranged to have in-turn practice to get familiar with practical operation of hotel and basic skill, while students in golf and leisure management can be trained in sport mechanism lab in the college to experience real environment.

Thirdly, it is field work experimental project. Through the way of organizing students to visit or investigate in field, it is able to cultivate students' ability of discovering and solving question. For instance, in the course of tourism resource development, teacher organized student to do the investigation in Daxian mountain, Luofu mountain, beach of Dongchong and Xichong, and students were asked to submit investigation report or presentation in a team or individual. While in some course such as the logistics management, students will go to visit some well-known logistic company to learn its procedure. Fourthly, it is simulated experimental project. Students can simulate to participate the activity of marketing, enterprise management, foreign trade practice, e-commerce, logistics management. These activities enable students practice real business situation, for example, campus cultural activities such as competition of travel route design, pioneering design competition, marketing planning contest, tourism cultural festival, website design competition, campus public advertisement competition, e-magazine design competition. All these activates foster students ability in teamwork, innovative practice and organization coordination, what's more, it broaden students' horizon by practicing the theory.

\subsubsection{The Stage of Disciplinary Application and Innovation}

Teaching lab at this stage will arrange experimental teaching curriculum based on synthetical dimension and innovation dimension. With better research condition, teaching lab at this stage mainly carries out classified, crossed and integrated experimental teaching for seniors and part of graduates. Moreover, it handles the job of research and development to cultivate students' innovative ability.

As a high level of experimental teaching, it is the experiment to encourage students' consciousness and initiative which mainly work on senior students. On one side, senior undergraduates can connect the experimental project with their graduate essay or design, the orientation of further study and employment.

On the other side, graduates can cultivate their academic ability, spot their research interests and form research mindset by participating in experimental project which mainly comes from teacher's research project or students' 
research hypothesis. Such as e-commerce project, planning on logistics management project, production and preview of marketing scheme, landscape design in scenic spot, maintenance of golf court etc. It also includes undergraduate's pioneering project competition, challenge competition and national project of undergraduate innovation experimental plan etc. All of them are important parts in this type of experiment.

\subsubsection{Stage of Industrial Application Research and Development}

Teaching lab at this stage arranges experimental teaching curriculum mainly based on innovation dimension and dynamic dimension. With favorable research condition, it works on open, comprehensive, applicable and research experimental teaching for graduates to carry out the job of research and development to cultivate students' applicable and research ability.

The focus at this stage is orienting to applicable research and development for society and industry. It is able to develop all kinds of academic projects under the background of collaboration of production, study and research which enable graduates serve society and enterprise on the base of experimental teaching centre. Persisting in academic spirit of independent innovation practice, teaching experimental centre arranges graduates to participate in teacher's scientific project. What's more, graduates are encouraged to actively seek the topic of project to propose their own hypothesis and research plan. Once the project is approved, the centre will offer comprehensive support in staff, capital, equipment and other aspects. And it is also the advantage and characteristics of integration education of undergraduates and graduates for graduates developing innovative research with undergraduates.

Above four stages are correlated. When students found deficiency of their own knowledge structure after experimental teaching curriculum, they can fill the vacancy by entering this experimental teaching centre to form complete and cycled experimental system to cover the whole teaching process. What's more, students can select the experiment course under teacher's guidance as their will, they can also actively design research learning experiment, or participate in teacher's academic or social application practice, or apply for various kinds of research projects such as undergraduate's innovation project and finish it on their own to broaden their horizon, master relevant technology and research method of modern tourism service management, foster scientific mind-set, exploitive spirit, innovation awareness and spirit to improve professional capacity.

\section{Conclusion}

Increasingly competitive times and industry sets higher requirement for professional staff of tourism management. So Tourism College and university have to have continuous exploitation and innovation in undergraduate and graduate education. And it is one of the effective channels to establish and improve tourism experimental teaching centre. Therefore, this paper constructs a cohesive experimental teaching system according to its disciplinary, crossed and graduate-oriented character of tourism management. Firstly, it contains five dimensions, that is, basic dimension, professional dimension, comprehensive dimension, innovative dimension and dynamic dimension. Secondly, under the precondition of crossed 5 dimensional features, it consists of 4 developing stages, that is, basic cognitive experiment, professional ability experiment, disciplinary application innovation and industrial application and research. In addition, the last two stages are the key to collaborative development of graduate and undergraduate education which supplies experimental platform for graduate's scientific research. Finally, this system possesses integrated, crossed and developmental feature which offer broader study and research chance for undergraduates and graduates. So it is an important platform to train compound innovation tourism talents.

\section{Acknowledgements}

This paper is supported by the Higher Education and Teaching Reform Project of Guangdong Province in 2012 with Grant Number 2012069, and Jinan University's graduate education Research Project with grant number 2010zd10.

\section{Reference}

Chen, W.-G. (2010). Research on experimental teaching in major of economic management. Scientific and technological information, 2010(14), 362-362.

Gu, W.-Y. (2006). Discussion on experimental teaching in major of economic management. Journal of South China Agricultural University (social science edition), 5(3), 152-156.

$\mathrm{Hu}$, M. (2010). Construction and discussion on operating management experimental teaching. South China financial computer, 2010(5), 98-100.

Li, Z.-G., \& Jiang, Y. (2006). Discussion on the construction of hospitality management experimental teaching 
system in major of tourism management. Tourism Tribune. Special issue on human resource and education, 55-58.

Li, Z.-R., \& Yao, G.-Q., \& Wang, Y.-H. (2005). Practice and thoughts on comprehensive lab construction in the major of economic management. Lab research and exploration, 2005(1), 34-34.

Liu, C.-H., \& Zhang, H.-Q. (2010). Promoting scientific development of lab, cultivating innovative practical talents. Modern educational equipment, 2010(15), 110-112.

Wang, D. (2010). Experimental teaching and cultivation of applicable medium talents. Press Circle, 2010(3), 171-175.

Wang, J.-W. (2010). University's Experimental teaching pattern and innovation in new era. Scientific management research, 2010(11), 121-124.

Wu, Y.-Z. (2010). Existing problems and improvement proposal on applicable experimental centre construction in university. Economist, 2010(8), 134-135.

Xie, X.-M., Wang, F.-P., Tang, S.-M., \& Zhang, J.-Y. (2005). Construction idea and operation pattern of experimental teaching centre. Lab research and exploration, 24(2), 103-107.

Yang, J. (2003). Preliminary discussion on open experimental teaching in university. Journal of Zhejing Normal university (natural science edition), 26(4), 414-415.

Yi, J.-Q. (2005). Lab is the support of modern compound university development. Lab research and exploration, $24(7), 1-4$

Zhang, L.-M. (1999). The time of globalization: International standards of China higher tourism education. Journal of Guilin Institute of tourism. Extra issue on tourism discipline construction and tourism education, 104-107.

Zhang, M., \& Zhao, X.-J., \& Luo, J. (2009). Innovation teaching system of tourism management experimental teaching centre. Lab research and exploration, 28(6), 222-227.

\section{Copyrights}

Copyright for this article is retained by the author(s), with first publication rights granted to the journal.

This is an open-access article distributed under the terms and conditions of the Creative Commons Attribution license (http://creativecommons.org/licenses/by/3.0/). 